Defraeye T., Blocken B., Carmeliet J. (2012), CFD simulation of heat transfer at surfaces of bluff bodies in turbulent boundary layers: evaluation of a forced-convective temperature wall function for mixed convection, Journal of Wind Engineering and Industrial Aerodynamics 104-106, 439-446. http://dx.doi.org/10.1016/i.jweia.2012.02.001

\title{
CFD simulation of heat transfer at surfaces of bluff bodies in turbulent boundary layers: evaluation of a forced-convective temperature wall function for mixed convection
}

\author{
Thijs Defraeye ${ }^{\mathrm{a}, \mathrm{b}}$, Bert Blocken ${ }^{\mathrm{c}}$, Jan Carmeliet ${ }^{\mathrm{d}, \mathrm{e}}$ \\ ${ }^{a}$ VCBT / MeBioS, Department of Biosystems, Katholieke Universiteit Leuven, Willem de Croylaan 42, 3001 \\ Heverlee, Belgium, thijs.defraeye@biw.kuleuven.be
}

${ }^{b}$ Laboratory of Building Physics, Department of Civil Engineering, Katholieke Universiteit Leuven, Kasteelpark Arenberg 40, 3001 Heverlee, Belgium

${ }^{c}$ Building Physics and Systems, Eindhoven University of Technology, P.O. Box 513, 5600 Eindhoven, The Netherlands, b.j.e.blocken@tue.nl

${ }^{d}$ Chair of Building Physics, Swiss Federal Institute of Technology Zurich (ETHZ), Wolfgang-Pauli-Strasse 15, 8093 Zürich, Switzerland, carmeliet@arch.ethz.ch

${ }^{e}$ Laboratory for Building Science and Technology, Swiss Federal Laboratories for Materials Testing and Research (Empa), Überlandstrasse 129, 8600 Dübendorf, Switzerland, jan.carmeliet@empa.ch

\section{Keywords}

wall function; computational fluid dynamics; buoyancy; convective heat transfer coefficient; cube; urban heat transfer; mixed convection 
Defraeye T., Blocken B., Carmeliet J. (2012), CFD simulation of heat transfer at surfaces of bluff bodies in turbulent boundary layers: evaluation of a forced-convective temperature wall function for mixed convection, Journal of Wind Engineering and Industrial Aerodynamics 104-106, 439-446. http://dx.doi.org/10.1016/i.jweia.2012.02.001

\begin{abstract}
$\underline{\text { Abstract }}$
Accurate predictions of convective heat transfer are essential in building-engineering and environmental studies on urban heat islands, building energy performance, (natural) building and inter-building ventilation and buildingenvelope durability and conservation. In computational fluid dynamics (CFD) studies of these applications, wall functions are mostly used to model the boundary-layer region. Recently, an adjusted wall function for temperature (CWF) has been proposed (Defraeye, T., Blocken, B., Carmeliet, J., 2011a.). This CWF was intended for forcedconvective heat transfer at surfaces of bluff bodies, such as buildings in the atmospheric boundary layer (ABL). This CWF provides increased (wall-function) accuracy for convective heat transfer predictions and can be easily implemented in existing CFD codes. As ABL flow around buildings is often in the mixed-convective regime, the CWF performance is evaluated for situations with mixed convection in this paper. The CWF accuracy for mixed convection ( $16 \%$ for the convective heat transfer coefficient, CHTC) is also much better than standard wall functions ( $47 \%$ for the CHTC), but is Richardson-number dependent. The CWF approach can therefore significantly improve the accuracy of forced- or mixed-convective heat transfer in large-scale building-engineering or environmental studies, which are bound to rely on wall functions, but where accurate convective heat transfer predictions are required.
\end{abstract}


Defraeye T., Blocken B., Carmeliet J. (2012), CFD simulation of heat transfer at surfaces of bluff bodies in turbulent boundary layers: evaluation of a forced-convective temperature wall function for mixed convection, Journal of Wind Engineering and Industrial Aerodynamics 104-106, 439-446. http://dx.doi.org/10.1016/j.jweia.2012.02.001

\section{Introduction}

Convective heat transfer predictions at surfaces of wall-mounted bluff bodies in turbulent boundary layers at moderate to high Reynolds numbers $\left(R e=10^{4}-10^{7}\right)$ are of interest for many engineering applications, such as building and urban engineering. Here, knowledge on wind-induced convective heat losses from exterior building surfaces or building components (e.g. solar collectors) in the atmospheric boundary layer (ABL) is relevant for the analysis of urban heat islands (e.g., Mochida et al., 1997; Murakami et al., 1999; Takebayashi and Moriyama, 2007; Sailor and Dietsch, 2007), building (component/envelope) energy performance (e.g., Liu and Harris, 2007; Palyvos, 2008), building-envelope durability or conservation (e.g., Blocken et al., 2007a; Hussein and El-Shishiny, 2009; Defraeye and Carmeliet, 2010) and (natural) ventilation of buildings (with outdoor air) and urban areas, i.e. interbuilding ventilation (e.g., Chen, 2009; van Hooff and Blocken, 2010; Luo and Li, 2011). Furthermore, such predictions can be used to estimate the convective moisture transfer from building surfaces, by using the heat and mass transfer analogy (e.g., Chilton and Colburn, 1934; Defraeye et al., 2012). Convective moisture transfer is of interest for hygrothermal analysis of building envelopes and for urban applications involving evaporation of water from ponds, roof ponds, green roofs, green walls or surfaces which are wetted by (wind-driven) rain (e.g., Blocken and Carmeliet, 2004).

Convective heat (or mass) transfer research for such flow problems is mainly performed by wind-tunnel experiments (Quintela and Viegas, 1995; Meinders et al., 1999; Barlow and Belcher, 2002; Barlow et al., 2004) or Computational Fluid Dynamics (CFD) studies (Blocken et al., 2009; Defraeye et al., 2010; Defraeye and Carmeliet, 2010; Defraeye et al., 2011b, Karava et al., 2011). CFD has the advantage, compared to wind-tunnel experiments, that a very high spatial resolution can be obtained (e.g. with respect to convective transfer coefficients; Defraeye et al., 2010) and that no restrictions are imposed regarding scaling and accessibility of certain surfaces (e.g. compared to infrared thermography; Meinders et al., 1998). On the other hand, the applied numerical modelling approaches (e.g. turbulence and boundary-layer modelling) determine to a large extent the accuracy of CFD simulations and should be validated.

Particularly at high Reynolds numbers $\left(R e \approx 10^{6}-10^{7}\right)$, such CFD computations are often performed with (steady) Reynolds-averaged Navier-Stokes (RANS) combined with wall functions (WFs), especially for complex configurations such as large-scale environmental studies (e.g., Hussein and El-Shishiny, 2009; van Hooff and Blocken, 2010; Gousseau et al., 2011). WFs are used here to take care of the boundary-layer region, instead of lowReynolds number modelling (LRNM). The main reason for this is computational economy: WFs avoid resolving the boundary layer explicitly, which would require an extremely high grid resolution for LRNM at high Reynolds numbers. Blocken et al. (2009) and Defraeye et al. (2010) have shown that resolving the laminar sublayer easily requires cell sizes smaller than $1 \mathrm{~mm}$, which is very difficult to achieve in extensive computational domains. Therefore, the use of WFs is often practically unavoidable.

The standard WFs (SWFs; Launder and Spalding, 1974) however have two main limitations: (1) Strict requirements to the computational grid are imposed: the cell centre point $\mathrm{P}$ of the wall-adjacent cells has to be located in the logarithmic layer $\left(30<y_{P}{ }^{+}<500\right)$. The dimensionless wall distance at point $\mathrm{P}\left(y_{P}{ }^{+}\right)$is defined as: 
Defraeye T., Blocken B., Carmeliet J. (2012), CFD simulation of heat transfer at surfaces of bluff bodies in turbulent boundary layers: evaluation of a forced-convective temperature wall function for mixed convection, Journal of Wind Engineering and Industrial Aerodynamics 104-106, 439-446. http://dx.doi.org/10.1016/j.jweia.2012.02.001

$\left(\tau_{w} / \rho\right)^{1 / 2} y_{P} / v$, where $y_{P}$ is the distance (normal) from the cell centre point $P$ of the wall-adjacent cell to the wall (m), $\tau_{w}$ is the shear stress at the wall $\left(\mathrm{kg} / \mathrm{ms}^{2}\right), \rho$ is the air density $\left(\mathrm{kg} / \mathrm{m}^{3}\right)$ and $v$ is the kinematic viscosity of air $\left(\mathrm{m}^{2} / \mathrm{s}\right)$. This grid requirement is often difficult to achieve throughout the entire computational domain for complex flows, especially if automated grid generation is used; (2) SWFs were derived for wall-attached boundary layers under socalled equilibrium conditions, i.e. small pressure gradients, local equilibrium between generation and dissipation of turbulent energy and a constant (uniform) shear stress and heat flux in the near-wall region (Casey and Wintergerste, 2000). For more complex flow problems, such as flow around bluff bodies, this wall-function concept breaks down. Here, SWFs can lead to inaccurate predictions, particularly for convective heat transfer (Launder, 1988).

In order to obviate these two limitations of SWFs to some extent, more advanced approaches have been developed, such as those by Shih et al. (2003), Craft et al. (2004), Popovac and Hanjalic (2007) and Balaji et al. (2008). These approaches aimed at developing a more generalised treatment for WFs, ensuring their validity throughout the entire boundary layer and thus not only in the logarithmic layer, and/or to improve the accuracy of WFs for complex non-equilibrium flows. The implementation of these adjusted WFs in commercial CFD codes is however not always that straightforward due to the limited access to the code itself. Furthermore, these adjusted WFs do not always improve the accuracy significantly compared to SWFs (e.g. Popovac and Hanjalic, 2007). Particularly for convective heat transfer, which is strongly determined by the transport in the boundary layer, more accurate alternatives for SWFs are required (Launder, 1988; Murakami, 1993; Blocken et al., 2009; Defraeye et al., 2010).

From the viewpoint of improved wall-function accuracy for convective heat transfer and ease of implementation in existing CFD codes, an adjustment to the standard temperature WF has been proposed by Defraeye et al. (2011a) (see also section 2). This WF was intended for applications of forced-convective heat transfer at surfaces of wallmounted (sharp-edged) bluff bodies in turbulent boundary layers at high Reynolds numbers, with a building in the $\mathrm{ABL}$ as a typical example. This adjusted WF significantly improves accuracy and can be easily implemented in existing CFD codes. This study was however performed for forced-convective flow, whereas in many large-scale urban engineering studies (e.g. Murakami et al., 1999; van Hooff and Blocken, 2010), air flow is in the mixedconvective regime, as this flow regime is predominantly found in urban areas. In this follow-up study, the performance of this customised (adjusted) temperature WF (CWF) is evaluated for similar applications (i.e. ABL flow over a cube) involving mixed convection, by comparison with SWF and LRNM simulations. In the next section, the background on the development of the CWF by Defraeye et al. (2011a) is briefly described.

\section{Customised wall function}

The adjusted temperature WF proposed by Defraeye et al. (2011a) aimed at combining a lower grid resolution in the near-wall region, compared to LRNM, together with an increased wall-function accuracy for convective heat transfer predictions, compared to the SWF. This customised temperature wall function (CWF) was derived from validated numerical LRNM data for air flow over a cube, as explained below, and was based on a logarithmic law:

$T_{P}^{*}=\operatorname{Pr}_{t, C W F}\left(\frac{1}{\kappa} \ln \left(E y_{P}^{*}\right)+P_{J}\left(\operatorname{Pr}_{t, C W F}\right)\right)$ 
Defraeye T., Blocken B., Carmeliet J. (2012), CFD simulation of heat transfer at surfaces of bluff bodies in turbulent boundary layers: evaluation of a forced-convective temperature wall function for mixed convection, Journal of Wind Engineering and Industrial Aerodynamics 104-106, 439-446. http://dx.doi.org/10.1016/j.jweia.2012.02.001

where $T_{P} *$ is the dimensionless temperature in the wall-adjacent cell centre point $\mathrm{P}, y_{P} *$ is the dimensionless wall distance in the wall-adjacent cell centre point $\mathrm{P}, \kappa$ is the von Karman constant $(0.4187), E$ is $9.793, \operatorname{Pr}_{t, C W F}$ is the turbulent Prandtl number used by the CWF and $P_{J}$ is an empirically-determined coefficient (see Fluent 12, 2009), which is a function of the turbulent Prandtl number $\left(P r_{t, C W F}\right)$. The parameters $y_{P} *, T_{P} *$ and $P_{J}$ are defined as:

$y_{P}^{*}=\frac{\rho C_{\mu}^{1 / 4} k_{P}^{1 / 2} y_{P}}{\mu}$

$T_{P}^{*}=\frac{\rho C_{\mu}^{1 / 4} k_{P}^{1 / 2}\left(T_{w}-T_{P}\right) c_{p}}{q_{c, w}}$

$P_{J}\left(\mathrm{Pr}_{t, C W F}\right)=9.24\left[\left(\frac{\mathrm{Pr}}{\mathrm{Pr}_{t, C W F}}\right)^{3 / 4}-1\right]\left[1+0.28 e^{-0.007 \mathrm{Pr}^{2} / \mathrm{Pr}_{,, C W F}}\right]$

where $\mu$ is the dynamic viscosity of air $(\mathrm{kg} / \mathrm{ms}), k_{P}$ is the turbulent kinetic energy in point $\mathrm{P}\left(\mathrm{m}^{2} / \mathrm{s}^{2}\right), C_{\mu}$ is $0.09, T_{P}$ is the air temperature in point $\mathrm{P}(\mathrm{K}), T_{w}$ is the wall temperature $(\mathrm{K}), q_{c, w}$ is the wall heat flux $\left(\mathrm{W} / \mathrm{m}^{2}\right), \operatorname{Pr}$ is the Prandtl number and $c_{p}$ is the specific heat capacity of air $(\mathrm{J} / \mathrm{kgK})$. Actually, the only difference between the CWF proposed by Defraeye et al. (2011a) and the SWF for temperature, implemented in the used CFD code (ANSYS Fluent), is that the CWF applies $P r_{t, C W F}=1.95$ instead of $P r_{t, S W F}=0.85$. Note that the CWF value was determined from validated LRNM data for actual wind flow over a bluff body (as explained in the next paragraph), while the SWF value was determined from flat-plate experiments under equilibrium conditions, which are less representative for building aerodynamics. Also note that for non-equilibrium flows, WFs (Eq.(1)) are defined based on $y^{*}$ (and $T^{*}$ ) values (related to the turbulent kinetic energy, Eqs.(2-3)) instead of $y^{+}$values (related to the wall shear stress, $\tau_{w}$ ). For boundary layers under equilibrium conditions, both parameters are equal (Launder, 1988).

This CWF (Eq.(1) with $\operatorname{Pr}_{t, C W F}=1.95$ ) was determined from the LRNM $T^{*}-y^{*}$ profiles of the thermal boundary layer on the surfaces of a cube. These profiles indicate a logarithmic-like behaviour and correspond well for different positions on the cube surfaces along lines normal to the surface. Such profiles are shown in Fig. 1 for the windward surface of the cube, as a function of the $y^{*}$ value, and similar profiles were found for the other surfaces of the cube (not shown, see Defraeye et al., 2011a). Note that the parameters used to calculate $y^{*}$ and $T^{*}$ (e.g. $k$ or $y$ ) vary with the distance from the wall. The proposed adjustment to the SWF was based on the quasi-universality of these LRNM $T^{*}-y^{*}$ profiles with respect to the surfaces, the position on the surface, the wind speed and wind direction (see Defraeye et al., 2011a). The CWF was obtained by fitting these validated numerical (LRNM) data for convective heat transfer in the turbulent region of the boundary layer by a logarithmic law (Eq.(1)), i.e. similar to that of SWFs. An example of such a logarithmic approximation is shown by line A in Fig. 1. Instead of the temperature SWF, which calculates $T_{P}{ }^{*}$ at point 1 in Fig. 1 , the CWF calculates the $T_{P}{ }^{*}$ value at point 2 (according to line A), which is much closer to the LRNM data. Since the predicted $T_{P} *$ value is used by WFs to calculate the wall heat flux $\left(q_{c, w}\right)$, the CWF provides a more accurate $q_{c, w}$ prediction. Consequently, also more accurate convective heat transfer coefficient $\left(\mathrm{CHTC}, \mathrm{W} / \mathrm{m}^{2} \mathrm{~K}\right)$ predictions are obtained, where $\mathrm{CHTC}=q_{c, w} /\left(T_{w}-T_{r e f}\right)$ with $T_{\text {ref }}=$ reference temperature (K). Note that line A does not represent the CWF of Eq.(1) (with $P r_{t, C W F}=1.95$ ) since the latter was also based on 
Defraeye T., Blocken B., Carmeliet J. (2012), CFD simulation of heat transfer at surfaces of bluff bodies in turbulent boundary layers: evaluation of a forced-convective temperature wall function for mixed convection, Journal of Wind Engineering and Industrial Aerodynamics 104-106, 439-446. http://dx.doi.org/10.1016/j.jweia.2012.02.001

data from other wind directions and of other surfaces (see Defraeye et al., 2011a). The actual CWF as implemented (i.e. with $\operatorname{Pr}_{t, C W F}=1.95$ ) is represented by line B. For more detailed information on the background and determination of the CWF, the reader is referred to Defraeye et al. (2011a).

The performance of the CWF was evaluated by Defraeye et al. (2011a) for several bluff-body configurations, including a cube. SWFs yielded deviations (overpredictions) for the CHTC of $40 \%$, on average, compared to LRNM. These deviations were generally reduced to about $10 \%$ or lower for the CWF, indicating a strong improvement in accuracy. In addition, this CWF can be easily implemented in existing CFD codes. In the CFD code that was used (ANSYS Fluent), $P r_{t}$ in Eq.(1) is called the Wall Prandtl Number, which could be easily adjusted (to $\left.P r_{t, C W F}\right)$ since it was directly accessible in the software. Note that the turbulent Prandtl number in the energy equation remains unchanged. One of the main limitations of this CWF is however that it was derived for forced-convective flow conditions. Therefore, the present study aims at evaluating its performance for mixed-convective flows. In the next two sections, the used numerical model and the CFD simulation details are discussed.

\section{Numerical model}

A cube with a height $(H)$ of $10 \mathrm{~m}$ is considered (Fig. 2), representing a building in the ABL. The size of the computational domain (Fig. 2) is determined according to the guidelines of Franke et al. (2007) and Tominaga et al. (2008). At the inlet of the domain, a neutral ABL over grass-covered terrain is imposed with a reference wind speed $\left(U_{10}\right)$ of $0.5 \mathrm{~m} / \mathrm{s}$, taken in the upstream undisturbed flow at building height $(10 \mathrm{~m})$. This results in a Reynolds number of $3.4 \times 10^{5}$, based on $H$ and $U_{10}$. The vertical profiles of the mean (horizontal) wind speed $U$ ( $\mathrm{m} / \mathrm{s}$, logarithmic law), turbulent kinetic energy $k\left(\mathrm{~m}^{2} / \mathrm{s}^{2}\right)$ and turbulence dissipation rate $\varepsilon\left(\mathrm{m}^{2} / \mathrm{s}^{3}\right)$ according to Richards and Hoxey (1993) are imposed:

$U(z)=\frac{u_{A B L}^{*}}{\kappa} \ln \left(\frac{z+z_{0}}{z_{0}}\right)$

$k=\frac{u_{A B L}^{*}{ }^{2}}{\sqrt{C_{\mu}}}$

$\varepsilon=\frac{u_{A B L}^{*}{ }^{3}}{\kappa\left(z+z_{0}\right)}$

where $u_{A B L} *$ is the ABL friction velocity $(\mathrm{m} / \mathrm{s}), z$ is the height above ground $(\mathrm{m})$ and $z_{0}$ is the aerodynamic roughness length $(0.03 \mathrm{~m})$. The temperature of the approach flow $\left(T_{r e f}\right)$ is $10^{\circ} \mathrm{C}$. The ground boundary is modelled as a no-slip boundary with zero roughness since surface roughness values cannot be specified if LRNM is used (Fluent 12, 2009). This restriction will inevitably introduce streamwise gradients in the vertical profiles of mean horizontal wind speed and turbulence (Blocken et al., 2007b; Blocken et al., 2007c) but this effect is rather limited since a short upstream fetch is considered, as recommended by Blocken et al. (2007b). The ground boundary is taken adiabatic. For the top and lateral boundaries, a symmetry boundary condition (slip wall) is used. Zero static pressure is imposed at the outlet. To investigate the influence of mixed convection on the CWF performance, CFD simulations at different Richardson numbers are performed. The Richardson number represents the importance of natural 
Defraeye T., Blocken B., Carmeliet J. (2012), CFD simulation of heat transfer at surfaces of bluff bodies in turbulent boundary layers: evaluation of a forced-convective temperature wall function for mixed convection, Journal of Wind Engineering and Industrial Aerodynamics 104-106, 439-446. http://dx.doi.org/10.1016/i.jweia.2012.02.001

convection relative to forced convection. Pure natural convection is considered as the case where there is no wind; mixed convection is used for all cases in between that and forced convection. Different Richardson numbers are achieved by varying the (uniform) temperature on the exterior cube surfaces $\left(T_{w}\right)$ from $10.1^{\circ} \mathrm{C}$ to $50^{\circ} \mathrm{C}$, resulting in Richardson numbers from 0.1 to 52 , which thus allows a comparison of forced convection with quasi fully buoyant flow. The use of a uniform surface temperature allowed a straightforward specification of the surface temperature in the Richardson number $(R i)$, which is defined as:

$R i=\frac{\beta g\left(T_{w}-T_{r e f}\right) H}{U_{10}^{2}}$

where $g$ is the gravitational acceleration $\left(9.81 \mathrm{~m} / \mathrm{s}^{2}\right)$ and $\beta$ is the thermal expansion coefficient of air, which can be approximated by $1 / T\left(\mathrm{~K}^{-1}\right)$. In this study, this temperature is taken equal to $\left(T_{w}-T_{r e f}\right) / 2$. For the forced-convective case, $R i=0$ as buoyancy is not taken into account. For these simulations, $T_{w}=20^{\circ} \mathrm{C}$ is imposed.

Appropriate grids are built, based on a grid-sensitivity analysis, consisting of $2.7 \times 10^{6}$ cells for LRNM (Fig. 2) and $1.6 \times 10^{6}$ cells for WFs. Both grids are hybrid grids (hexahedral and prismatic cells). In order to resolve the boundary layer appropriately, LRNM grids require a higher cell density in the wall-normal direction and a smaller $y^{+}$ value of the wall-adjacent cell $\left(y_{P}{ }^{+} \approx 1\right)$, compared to WFs $\left(30<y_{P}{ }^{+}<500\right)$. Since $\tau_{w}$ increases with increasing wind speed $\left(U_{10}\right)$, the evaluation of higher wind speeds with LRNM requires locally a higher grid resolution in the boundary-layer region, hence a lower $y_{P}$, in order to obtain a $y_{P}{ }^{+}$of about 1 . The required $y_{P}$ can therefore become very small for LRNM at high Reynolds numbers ( $\pm 0.05 \mathrm{~mm}$ for $U_{10}=7.5 \mathrm{~m} / \mathrm{s}$; see Defraeye et al., 2011b). Such a high grid resolution for LRNM at high Reynolds numbers can significantly increase the computational expense, and can also entail considerable problems for grid generation and convergence rates. These are actually the main reasons to employ WFs at high Reynolds numbers. Relatively low wind speeds $\left(U_{10}\right)$ are therefore used in this study to limit $y_{P}$ for LRNM grids to some extent (see Defraeye et al., 2011b). The total number of LRNM cells is actually still relatively small for this isolated building. However, computationally-expensive large-scale building-engineering or environmental studies using LRNM might become quasi impossible because LRNM yields too many cells. In this case, using WFs is the only option.

The wall-function grid has the same cell density as the LRNM grid outside the near-wall region, but in the nearwall region the grid is adapted in order to provide: (1) a higher $y_{P}{ }^{*}$ value (> 30) for the wall-adjacent cells $\left(y_{P}{ }^{+}\right.$values are only used by wall functions for equilibrium boundary-layer flows); (2) a smooth transition with the second and successive wall-normal cells, with respect to grid stretching.

\section{Numerical simulation}

The simulations are performed with the CFD code ANSYS Fluent 12. Steady RANS is used in combination with a turbulence model. The realizable k- $\varepsilon$ model (Shih et al., 1995) is used together with LRNM and WFs for the boundary-layer region. 
Defraeye T., Blocken B., Carmeliet J. (2012), CFD simulation of heat transfer at surfaces of bluff bodies in turbulent boundary layers: evaluation of a forced-convective temperature wall function for mixed convection, Journal of Wind Engineering and Industrial Aerodynamics 104-106, 439-446. http://dx.doi.org/10.1016/i.jweia.2012.02.001

The accuracy of CFD simulations depends to a large extent on the turbulence-modelling and boundary-layer modelling approaches that are used. It has to be quantified by means of validation experiments/simulations. The realizable k- $\varepsilon$ turbulence model with LRNM (Wolfshtein model; Wolfshtein, 1969) was recently evaluated in a CFD validation study (Defraeye et al., 2010) using wind-tunnel measurements (Meinders et al., 1999) of convective heat transfer on the surfaces of a cube placed in turbulent channel flow at a Reynolds number of $4.6 \times 10^{3}$, based on the cube height and the bulk wind speed. The CFD validation study produced accurate CHTC predictions, both in magnitude and distribution over the surface, for the windward surface (within the experimental uncertainty of 5\%), and to a lesser extent for the leeward surface (differences with experimental data $<10 \%$ ), except at the edge zones, which was attributed to the limited resolution of the experiments in these zones. For the side and top surfaces, the distribution of the CHTC predictions over these surfaces was less accurate. These discrepancies were rather attributed to inaccurate flow predictions in zones of separation and recirculation around bluff bodies (Murakami et al., 1996; Iaccarino et al., 2003), due to steady-flow and turbulence modelling, than to inaccurate heat transfer modelling in the boundary layer. Such discrepancies are a well-known deficiency of the steady RANS approach combined with two-equation turbulence models. Although more advanced turbulence modelling approaches, for example large-eddy simulation or direct numerical simulation, could result in more accurate CHTC results on these surfaces, steady RANS is still often preferred for complex configurations at high Reynolds numbers for reasons of computational economy (e.g., Hussein and El-Shishiny, 2009; van Hooff and Blocken, 2010; Gousseau et al., 2011; van Hooff et al., 2011). Based on this perspective, it was also used in this study. Note that the validation study (Defraeye et al., 2010) was performed for forced convection, and similar experimental data, particularly suitable for detailed CFD validation, were not available, to date, for mixed convection. CFD, and more in particular the RANS approach, has been used in the past for mixed convective studies in urban areas (Xie et al., 2006; 2007; Cheng et al., 2009), but only few studies exist. Passive scalar transfer (forced convection) is more often studied.

Radiation is not considered in the simulations since fixed temperature boundary conditions are used for the surfaces of the cube. The density is modelled with the Boussinesq approximation to account for buoyancy effects. Thereby, heat will act as an active scalar and the flow field will be dependent of the imposed thermal boundary conditions. Furthermore, second-order discretisation schemes are used throughout. The SIMPLE algorithm is used for pressure-velocity coupling. Pressure interpolation is second order. Convergence was assessed by monitoring the velocity, turbulent kinetic energy and temperature on specific locations in the flow field and heat fluxes on the surfaces of the cube.

\section{$\underline{\text { 5. Results and discussion }}$}

\subsection{Impact of buoyancy on convective heat transfer}

Prior to assessing the performance of the CWF for mixed convection, the impact of buoyancy on the CHTC distribution on the surfaces of the cube, as calculated by steady RANS with LRNM, is illustrated in Fig. 3. Here, the CHTC distribution on the different cube surfaces is reported in a vertical and horizontal centreplane for different Richardson numbers, i.e. from 0.1 to 52 (temperature differences $\Delta T=T_{w}-T_{r e f}$ of $0.1^{\circ} \mathrm{C}$ to $40^{\circ} \mathrm{C}$ ) and also for forced convection. It is clear that the CHTC increases for all surfaces with increasing Richardson number, especially for the 
Defraeye T., Blocken B., Carmeliet J. (2012), CFD simulation of heat transfer at surfaces of bluff bodies in turbulent boundary layers: evaluation of a forced-convective temperature wall function for mixed convection, Journal of Wind Engineering and Industrial Aerodynamics 104-106, 439-446. http://dx.doi.org/10.1016/i.jweia.2012.02.001

leeward surface. The shape of the CHTC distribution for the mixed-convective cases mainly differs from the forcedconvective case at the bottom of the windward surface, i.e. at the frontal vortex, and at the top of the leeward surface (Fig. 3a). At the highest Richardson number $\left(R i=52, \Delta T=40^{\circ} \mathrm{C}\right)$, the horizontal CHTC distribution at the leeward surface (Fig. 3b) is not symmetrical anymore, which clearly indicates the impact of buoyancy on the stability of the steady RANS solution of this symmetrical configuration. For Richardson numbers below $0.1(\Delta T=0.1 \mathrm{~K})$, buoyancy effects can be considered negligible. Note that in all simulations, a neutral approach flow ABL is assumed, whereas in reality, also a stratified ABL (stable or unstable) can occur. The focus of this paper is however on demonstrating the performance of the CWF, which is related to the thermal flow field close to the building. For this reason, thermal stability of the approach flow is not considered in this study, as this will not lead to a better indication of the performance of the CWF, compared to SWFs.

\subsection{Evaluation of wall-function accuracy}

In Fig. 4, the CHTC distribution on the surfaces of the cube in a vertical centreplane is given for LRNM, the SWF and the CWF for forced convection and for all mixed-convective cases. Each case is represented in a separate graph. In addition, the relative differences between the surface-averaged CHTC, calculated by LRNM $\left(\mathrm{CHTC}_{\mathrm{LRNM}}\right)$ and by the SWF or the CWF $\left(\mathrm{CHTC}_{\mathrm{WF}}\right)$, are compared for all surfaces of the cube as a function of the temperature difference $(\Delta T)$ in Fig. 5. Note that the cube-averaged CHTC is also shown here, including both side surfaces. Note that the CHTC is directly representative for the heat flux at the wall $\left(q_{c, w}\right)$ since $T_{w}$ (and thus also $\Delta T$ ) is constant over all building surfaces.

The overprediction of the CHTC by SWFs, compared to LRNM, can clearly be noticed for forced convection ( \pm $50 \%$ of $\mathrm{CHTC}_{\mathrm{LRNM}}$ for forced convection) but also for all mixed-convective cases. A distinct similarity in the CHTC distribution over the surfaces is however found between LRNM and SWFs for forced convection (Fig. 4), which is related to the similarity of the flow fields (e.g. the location of the separation and recirculation zones). This similarity breaks down partially at higher Richardson numbers, since the flow field will also be influenced by buoyancy effects (i.e. the predicted heat flows from building surfaces), which are significantly different for SWFs and LRNM. Note that SWFs for momentum transport do not result in worse overall flow predictions for this sharp-edged bluff body at

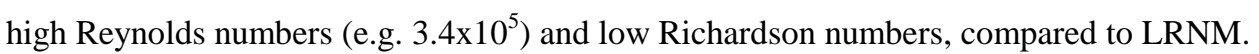

The CWF results show a very good agreement with LRNM for forced convection, as already shown by Defraeye et al. (2011a). The accuracy of the CWF, compared to LRNM, decreases to some extent for mixed convection at high Richardson numbers. However, in most cases the deviations for a specific surface are smaller than 15\% and in all cases smaller than 30\% (see Fig. 5). The deviations of the CWF with respect to the cube-averaged CHTC are below $16 \%$ for all Richardson numbers. For the SWF on the other hand, the deviations are above $47 \%$. The CWF thus remains much more accurate than the SWF, also for mixed-convective cases, and is therefore a significantly better alternative for the SWF.

Although the issue regarding the applicability of the CWF for mixed-convective flows was clarified in this study, other issues regarding the use of this CWF are still pending. These are discussed in detail by Defraeye et al. (2011a) 
Defraeye T., Blocken B., Carmeliet J. (2012), CFD simulation of heat transfer at surfaces of bluff bodies in turbulent boundary layers: evaluation of a forced-convective temperature wall function for mixed convection, Journal of Wind Engineering and Industrial Aerodynamics 104-106, 439-446. http://dx.doi.org/10.1016/j.jweia.2012.02.001

and are not all repeated here. One issue which will certainly be addressed in future work is the performance of the CWF for dense bluff-body configurations, such as in urban areas (e.g. street canyons or building arrays). Although some work has already been done on this behalf (Allegrini et al., 2012), further CWF performance evaluation is still required, and ongoing. Note that a similar adjusted WF can be determined for convective mass transfer. In the context of urban heat island mitigation, this can be useful to predict evaporation of water from building and urban surfaces more accurately.

\section{Conclusions}

The performance of an adjusted temperature wall function, originally developed for forced-convective flow around wall-mounted (sharp-edged) bluff bodies in turbulent boundary layers at moderate to high Reynolds numbers, was evaluated in this study for mixed convection. This customised wall function (CWF) can provide a strongly increased accuracy for forced-convective heat transfer and is easily implementable in existing CFD codes. The evaluation of this CWF for mixed convection was done in this study for atmospheric boundary layer flow over a cubic building, by comparison with validated low-Reynolds number modelling (LRNM) simulations. Even for mixed convection, the CWF showed much more accurate convective heat transfer predictions than standard wall functions (SWFs): differences with LRNM results of the cube-averaged convective heat transfer coefficient (CHTC) were below 16\% for the evaluated Richardson number range (0-52), whereas they were above $47 \%$ for SWFs. Note that the CWF accuracy was to some extent dependent on the Richardson number and on the surface considered. The CWF approach combines increased wall-function accuracy for convective heat transfer calculations with the typical advantages of WFs compared to LRNM, namely easier grid generation, since very fine cells in the near-wall region are avoided, and grids with less computational cells, reducing the computational time. The CWF approach will thus be useful for computationally-expensive large-scale building-engineering or environmental studies involving forcedor mixed-convective heat transfer, which are bound to rely on WFs to resolve the transfer in the boundary layer, but where accurate convective heat transfer predictions are required.

\section{Acknowledgements}

Thijs Defraeye is a postdoctoral fellow of the Research Foundation - Flanders (FWO). The Academische Stichting Leuven provided funding for him to attend the $13^{\text {th }}$ International Conference on Wind Engineering, which is gratefully acknowledged. These sponsors had no involvement in: the study design, the collection, analysis and interpretation of data; the writing of the manuscript; and the decision to submit the manuscript for publication. The authors are grateful to Prof. Yukio Tamura of Tokyo Polytechnic University for his willingness to act as an Editor for this paper and for his excellent management of the review process.

\section{$\underline{\text { References }}$}

Allegrini, J., Dorer, V., Defraeye, T., Carmeliet, J., 2012. An adaptive temperature wall function for mixed convective flows at exterior surfaces of buildings in street canyons. Build. Environ. 49, 55-66.

Balaji, C., Hölling, M., Herwig, H., 2008. A temperature wall function for turbulent mixed convection from vertical, parallel plate channels. Int. J. Therm. Sci. 47 (6), 723-729. 
Defraeye T., Blocken B., Carmeliet J. (2012), CFD simulation of heat transfer at surfaces of bluff bodies in turbulent boundary layers: evaluation of a forced-convective temperature wall function for mixed convection, Journal of Wind Engineering and Industrial Aerodynamics 104-106, 439-446. http://dx.doi.org/10.1016/i.jweia.2012.02.001

Barlow, J.F., Belcher, S.E., 2002. A wind tunnel model for quantifying fluxes in the urban boundary layer. Bound.Lay. Meteorol. 104 (1), 131-150.

Barlow, J.F., Harman, I.N., Belcher, S.E., 2004. Scalar fluxes from urban street canyons part 1: Laboratory simulation. Bound.-Lay. Meteorol. 113 (3), 369-385.

Blocken, B., Carmeliet, J., 2004. A review of wind-driven rain research in building science. J. Wind Eng. Ind. Aerod. 92 (13), 1079-1130.

Blocken, B., Defraeye, T., Derome, D., Carmeliet, J., 2009. High-resolution CFD simulations for forced convective heat transfer coefficients at the facade of a low-rise building. Build. Environ. 44 (12), 2396-2412.

Blocken, B., Roels, S., Carmeliet, J., 2007a. A combined CFD-HAM approach for wind-driven rain on building facades. J. Wind Eng. Ind. Aerod. 95 (7), 585-607.

Blocken, B., Stathopoulos, T., Carmeliet, J., 2007b. CFD simulation of the atmospheric boundary layer: wall function problems. Atmos. Environ. 41 (2), 238-252.

Blocken, B., Carmeliet, J., Stathopoulos, T., 2007c. CFD evaluation of the wind speed conditions in passages between buildings - effect of wall-function roughness modifications on the atmospheric boundary layer flow. J. Wind Eng. Ind. Aerod. 95 (9-11), 941-962.

Casey, M., Wintergerste, T., 2000. Best Practice Guidelines. ERCOFTAC Special Interest Group on "Quality and Trust in Industrial CFD”. ERCOFTAC.

Chen, Q., 2009. Ventilation performance prediction for buildings: A method overview and recent applications. Build. Environ. 44 (4), 848-858.

Cheng, W.C., Liu, C.-H., Leung, D.Y.C., 2009. On the correlation of air and pollutant exchange for street canyons in combined wind-buoyancy-driven flow. Atmos. Environ. 43 (24), 3682-3690.Chilton, T.H., Colburn, A.P., 1934. Mass transfer (absorption) coefficients. Ind. Eng. Chemistry 26, 1183-1187.

Craft, T.J., Gant, S.E., Iacovides, H., Launder, B.E., 2004. A new wall function strategy for complex turbulent flows. Numer. Heat Tr. B - Fund. 45 (4), 301-318.

Defraeye, T., Blocken, B., Carmeliet, J., 2010. CFD analysis of convective heat transfer at the surfaces of a cube immersed in a turbulent boundary layer. Int. J. Heat Mass Tran. 53 (1-3), 297-308.

Defraeye, T., Blocken, B., Carmeliet, J., 2011a. An adjusted temperature wall function for turbulent forced convective heat transfer for bluff bodies in the atmospheric boundary layer. Build. Environ. 46 (11), $2130-2141$.

Defraeye, T., Blocken, B., Carmeliet, J., 2011b. Convective heat transfer coefficients for exterior building surfaces: Existing correlations and CFD modelling. Energ. Convers. Manage. 52 (1), 512-522.

Defraeye, T., Carmeliet, J., 2010. A methodology to assess the influence of local wind conditions and building orientation on the convective heat transfer at building surfaces. Environ. Modell. Softw. 25 (12), 1813-1824.

Defraeye, T., Blocken, B., Carmeliet, J., 2012. Analysis of convective heat and mass transfer coefficients for convective drying of a porous flat plate by conjugate modelling. Int. J. Heat Mass Tran. 55 (1-3), 112-124.

Fluent 12, 2009. Ansys Fluent 12.0 User's Guide, Ansys Inc.

Franke, J., Hellsten, A., Schlünzen, H., Carissimo, B., 2007. Best practice guideline for the CFD simulation of flows in the urban environment. COST Action 732: Quality assurance and improvement of microscale meteorological models, Hamburg, Germany. 
Defraeye T., Blocken B., Carmeliet J. (2012), CFD simulation of heat transfer at surfaces of bluff bodies in turbulent boundary layers: evaluation of a forced-convective temperature wall function for mixed convection, Journal of Wind Engineering and Industrial Aerodynamics 104-106, 439-446. http://dx.doi.org/10.1016/i.jweia.2012.02.001

Gousseau, P., Blocken, B., Stathopoulos, T., van Heijst, G.J.F., 2011. CFD simulation of near-field pollutant dispersion on a high-resolution grid: A case study by LES and RANS for a building group in downtown Montreal. Atmos. Environ. 45 (2), 428-438.

Hussein, A.S., El-Shishiny, H., 2009. Influences of wind flow over heritage sites: A case study of the wind environment over the Giza Plateau in Egypt. Environ. Modell. Softw. 24 (3), 389-410.

Iaccarino, G., Ooi, A., Durbin, P.A., Behnia, M., 2003. Reynolds averaged simulation of unsteady separated flow. Int. J. Heat Fluid Fl. 24 (2), 147-156.

Karava, P., Jubayer, C.M., Savory, E., 2011. Numerical modelling of forced convective heat transfer from the inclined windward roof of an isolated low-rise building with application to photovoltaic/thermal systems. Appl. Therm. Eng. 31 (11-12), 1950-1963.

Launder, B.E., 1988. On the computation of convective heat transfer in complex turbulent flows. T. ASME: J. Heat Trans. 110, 1112-1128.

Launder, B.E., Spalding, D.B., 1974. The numerical computation of turbulent flows. Comput. Method. Appl. M. Eng. 3 (2), 269-289.

Liu, Y., Harris, D.J., 2007. Full-scale measurements of convective coefficient on external surface of a low-rise building in sheltered conditions. Build. Environ. 42 (7), 2718-2736.

Luo, Z., Li, Y., 2011. Passive urban ventilation by combined buoyancy-driven slope flow and wall flow: Parametric CFD studies on idealized city models. Atmos. Environ. 45 (32), 5946-5926.

Meinders, E.R., Van Der Meer, T.H., Hanjalic, K., 1998. Local convective heat transfer from an array of wallmounted cubes. Int. J. Heat Mass Tran. 41 (2), 335-346.

Meinders, E.R., Hanjalic, K., Martinuzzi, R.J., 1999. Experimental study of the local convection heat transfer from a wall-mounted cube in turbulent channel flow. T. ASME: J. Heat Trans. 121 (3), 564-573.

Mochida, A., Murakami, S., Ojima, T., Kim, S., Ooka, R., Sugiyama, H., 1997. CFD analysis of mesoscale climate in the Greater Tokyo area. J. Wind Eng. Ind. Aerod. 67-68, 459-477.

Murakami, S., 1993. Comparison of various turbulence models applied to a bluff body. J. Wind Eng. Ind. Aerod. 46$47,21-36$

Murakami, S., Mochida, A., Ooka, R., Kato, S., Iizuka, S., 1996. Numerical prediction of flow around a building with various turbulence models: comparison of k- $\varepsilon$ EVM, ASM, DSM and LES with wind tunnel tests. ASHRAE Trans. 102 (1), 741-753.

Murakami, S., Ooka, R., Mochida, A., Yoshida, S., Kim, S., 1999. CFD analysis of wind climate from human scale to urban scale. J. Wind Eng. Ind. Aerod. 81 (1-3), 57-81.

Palyvos, J.A., 2008. A survey of wind convection coefficient correlations for building envelope energy systems' modelling. Appl. Therm. Eng. 28 (8-9), 801-808.

Popovac, M., Hanjalic, K., 2007. Compound wall treatment for RANS computation of complex turbulent flows and heat transfer. Flow Turbul. Combust. 78 (2), 177-202.

Quintela, D.A., Viegas, D.X., 1995. Convective heat losses from buildings, in: Cermak, J.E., Davenport, A.G., Plate, E.J., Viegas, D.X. (Eds.), Wind Climate in Cities. Kluwer Academic Publishers, The Netherlands, pp. 503-522.

Richards, P.J., Hoxey, R.P., 1993. Appropriate boundary conditions for computational wind engineering models using the k- $\varepsilon$ turbulence model. J. Wind Eng. Ind. Aerod. 46-47, 145-153. 
Defraeye T., Blocken B., Carmeliet J. (2012), CFD simulation of heat transfer at surfaces of bluff bodies in turbulent boundary layers: evaluation of a forced-convective temperature wall function for mixed convection, Journal of Wind Engineering and Industrial Aerodynamics 104-106, 439-446. http://dx.doi.org/10.1016/i.jweia.2012.02.001

Sailor, D.J., Dietsch, N., 2007. The urban heat island Mitigation Impact Screening Tool (MIST). Environ. Modell. Softw. 22 (10), 1529-1541.

Shih, T.H., Liou, W.W., Shabbir, A., Yang, Z., Zhu, J., 1995. A new k- $\varepsilon$ eddy viscosity model for high Reynolds number turbulent flows. Comput. Fluids 24 (3), 227-238.

Shih, T.H., Povinelli, L.A., Liu, N.S., 2003. Application of generalized wall function for complex turbulent flows. J. Turb. 4 (1), 1-16.

Takebayashi, H., Moriyama, M., 2007. Surface heat budget on green roof and high reflection roof for mitigation of urban heat island. Build. Environ. 42 (8), 2971-2979.

Tominaga, Y., Mochida, A., Yoshie, R., Kataoka, H., Nozu, T., Yoshikawa, M., Shirasawa, T., 2008. AIJ guidelines for practical applications of CFD to pedestrian wind environment around buildings. J. Wind Eng. Ind. Aerod. 96 (10-11), 1749-1761.

van Hooff, T., Blocken, B., 2010. Coupled urban wind flow and indoor natural ventilation modelling on a highresolution grid: a case study for the Amsterdam ArenA stadium. Environ. Modell. Softw. 25 (1), 51-65.

van Hooff, T., Blocken, B., van Harten, M., 2011. 3D CFD simulations of wind flow and wind-driven rain shelter in sports stadia: Influence of stadium geometry. Build. Environ. 46 (1), 22-37.

Wolfshtein, M., 1969. The velocity and temperature distribution in one-dimensional flow with turbulence augmentation and pressure gradient. Int. J. Heat Mass Tran. 12 (3), 301-318.

Xie, X., Liu, C.H., Leung, Y.C., Leung, K.H, 2006. Characteristics of air exchange in a street canyon with ground heating. Atmos. Environ. 40 (33), 6396-6409.

Xie, X., Liu, C.H., Leung, Y.C., 2007. Impact of building facades and ground heating on wind flow and pollutant transport in street canyons. Atmos. Environ 41, 9030-9049. 
Defraeye T., Blocken B., Carmeliet J. (2012), CFD simulation of heat transfer at surfaces of bluff bodies in turbulent boundary layers: evaluation of a forced-convective temperature wall function for mixed convection, Journal of Wind Engineering and Industrial Aerodynamics 104-106, 439-446. http://dx.doi.org/10.1016/j.jweia.2012.02.001

\section{Figure captions}

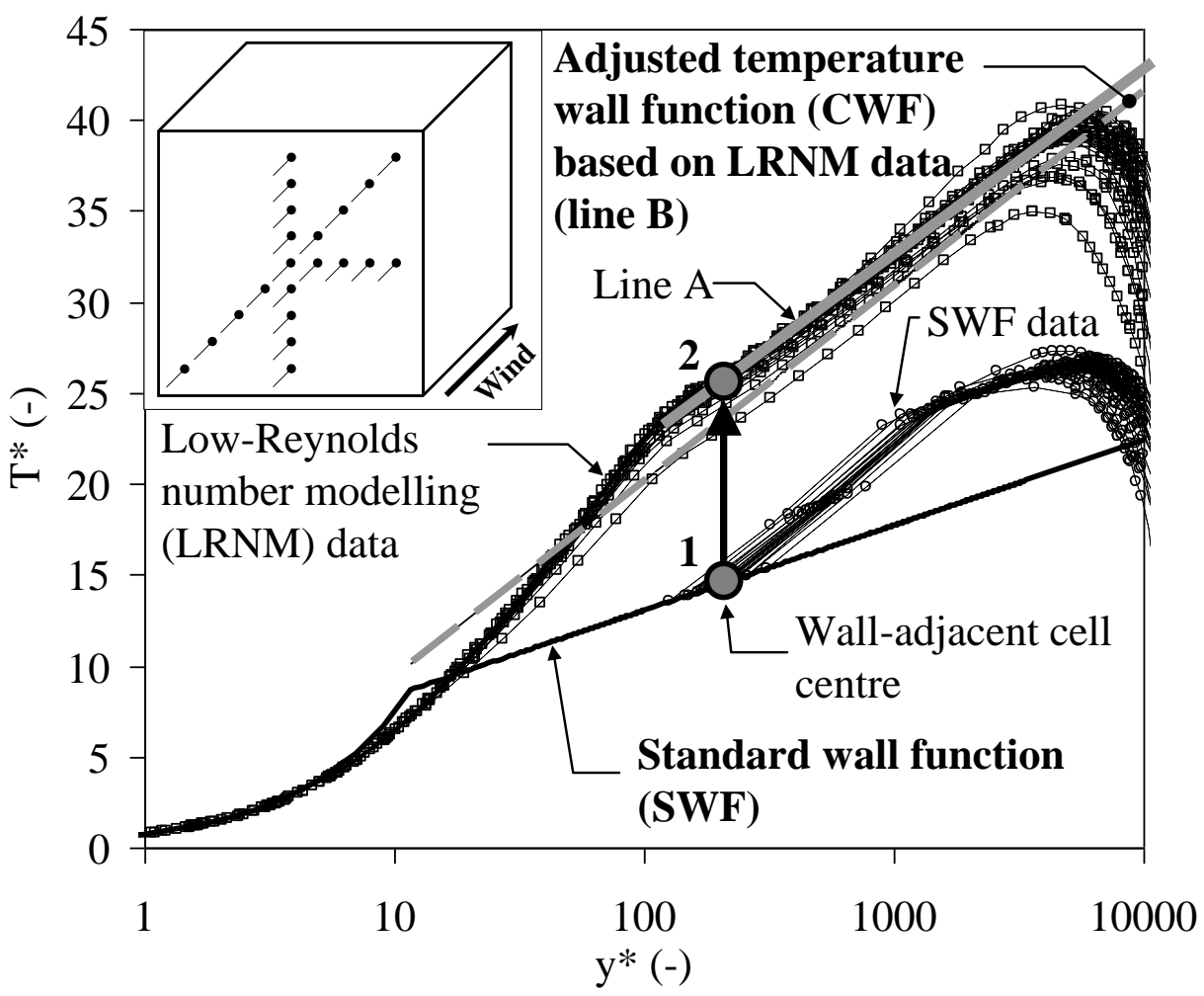

Figure 1. Dimensionless

temperature profiles $\left(T^{*}\right)$ at different positions on the windward surface of the cube (for wind direction perpendicular to the surface) along lines normal to the surface, as a function of the $y^{*}$ value (logarithmic scale), for LRNM and SWFs. The CWF approximation of the LRNM data (as implemented in the CFD code; see Defraeye et al., 2011a) is shown by line B.
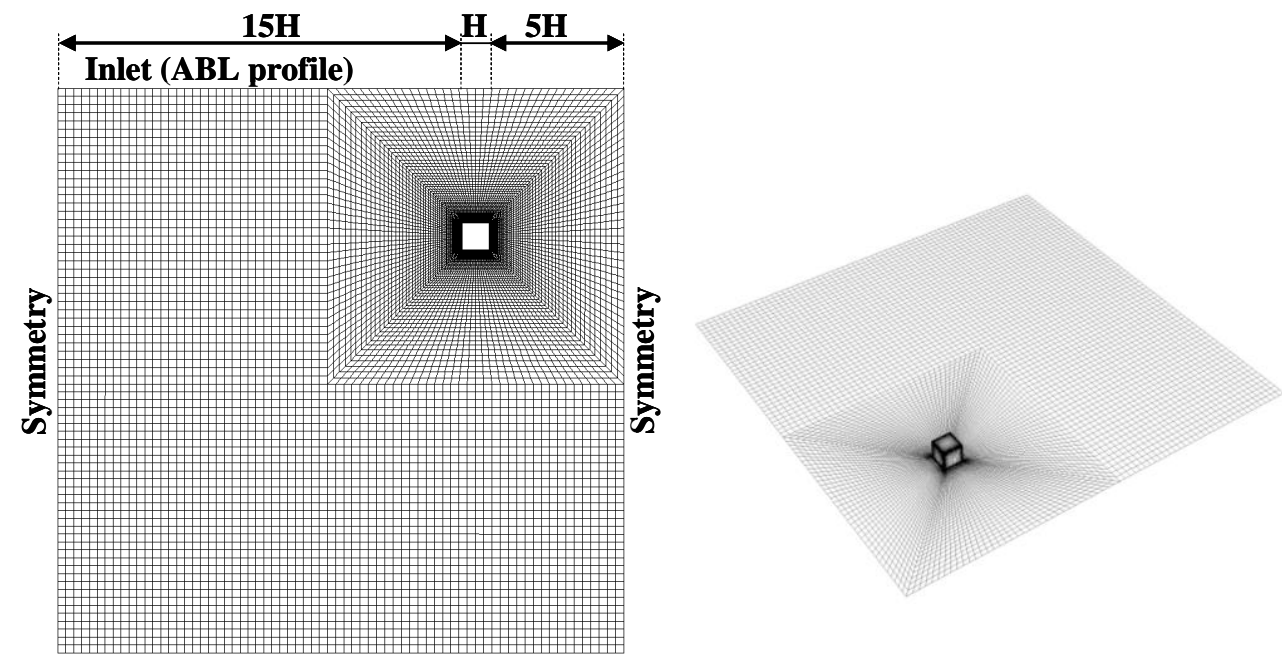

Outlet (zero static pressure)

Figure 2. Computational domain and grid $(H=$ cube height $)$ with specification of the boundary conditions. The height of the domain is $6 H$. Top view (left) and isometric view (right). 
Defraeye T., Blocken B., Carmeliet J. (2012), CFD simulation of heat transfer at surfaces of bluff bodies in turbulent boundary layers: evaluation of a forced-convective temperature wall function for mixed convection, Journal of Wind Engineering and Industrial Aerodynamics 104-106, 439-446.

http://dx.doi.org/10.1016/j.jweia.2012.02.001
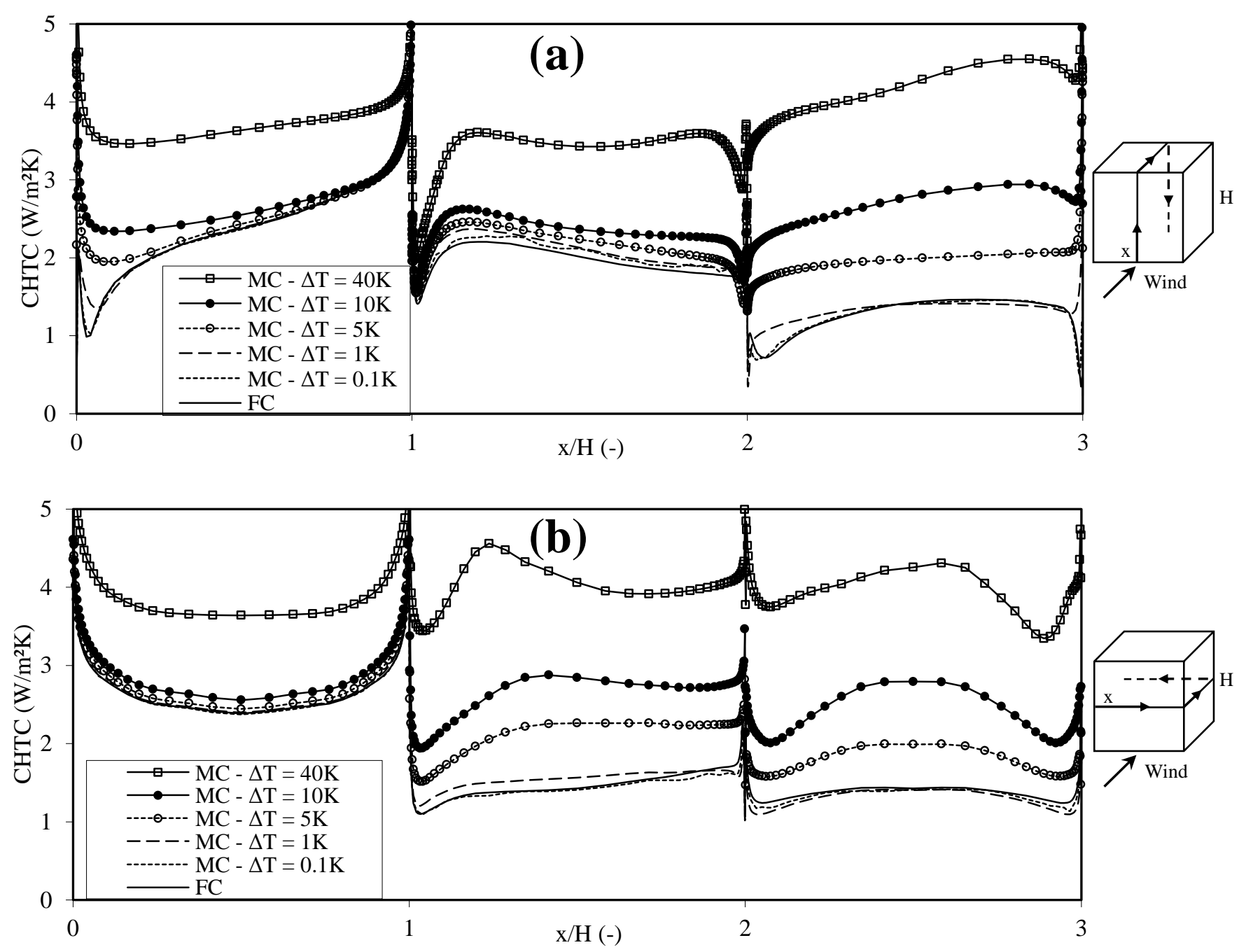

Figure 3. CHTC distribution on the surfaces of the cube (for LRNM) in a vertical (a) and horizontal (b) centreplane for forced and mixed convection (MC: mixed convection, FC: forced convection). 
Defraeye T., Blocken B., Carmeliet J. (2012), CFD simulation of heat transfer at surfaces of bluff bodies in turbulent boundary layers: evaluation of a forced-convective temperature wall function for mixed convection, Journal of Wind Engineering and Industrial Aerodynamics 104-106, 439-446. http://dx.doi.org/10.1016/j.jweia.2012.02.001
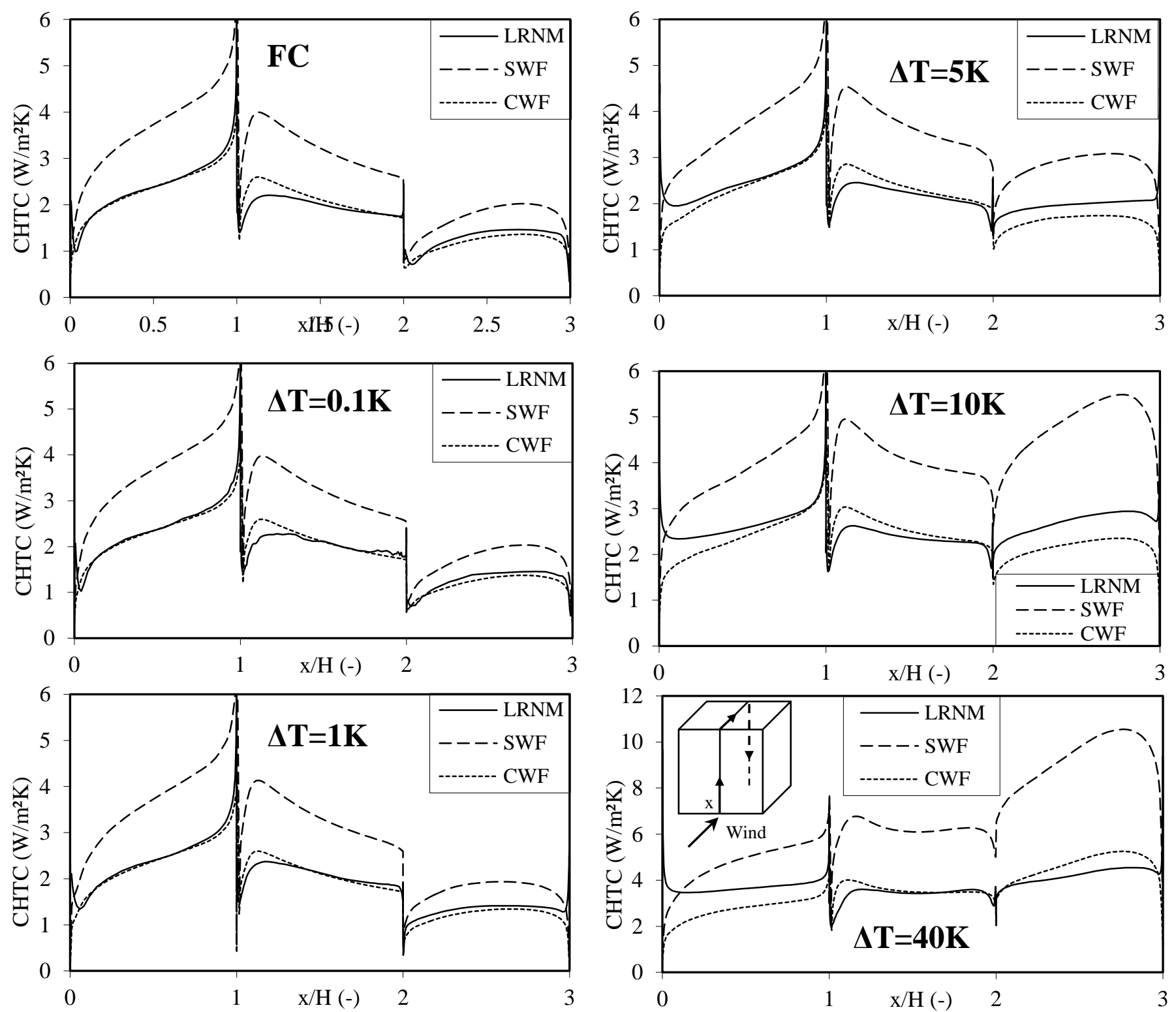

Figure 4. CHTC distribution on the surfaces of the cube (for LRNM, SWF and CWF) in a vertical centreplane for forced convection (FC) and all mixed-convective cases. Note that the scale on the vertical axis is different for $\Delta T=$ $40 \mathrm{~K}$. 
Defraeye T., Blocken B., Carmeliet J. (2012), CFD simulation of heat transfer at surfaces of bluff bodies in turbulent boundary layers: evaluation of a forced-convective temperature wall function for mixed convection, Journal of Wind Engineering and Industrial Aerodynamics 104-106, 439-446.

http://dx.doi.org/10.1016/.jweia.2012.02.001

\section{Standard wall function (SWF)}

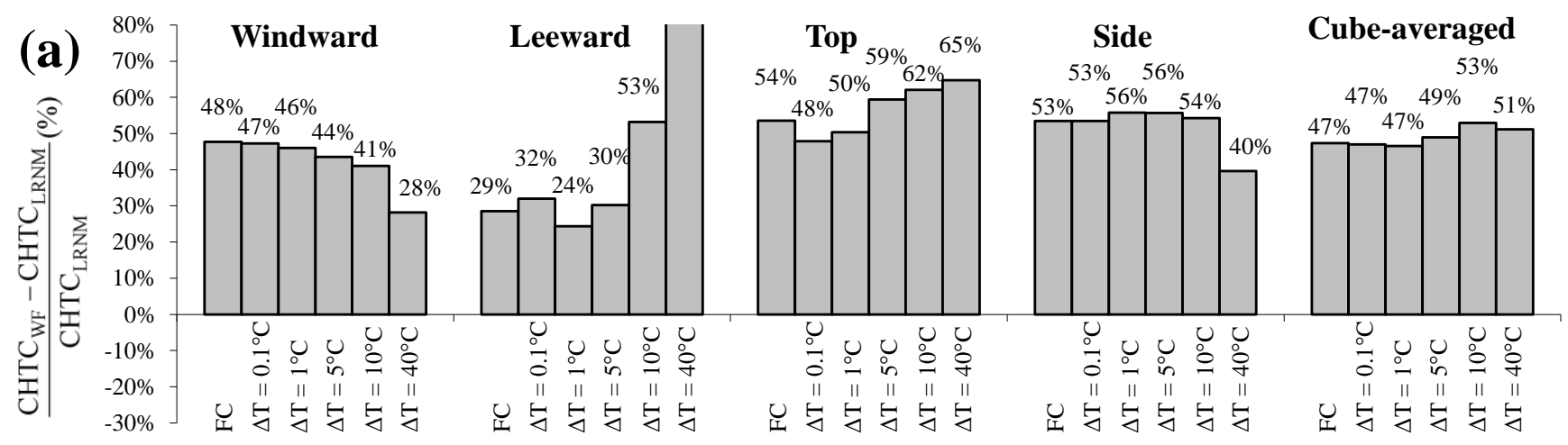

\section{Adjusted wall function (CWF)}

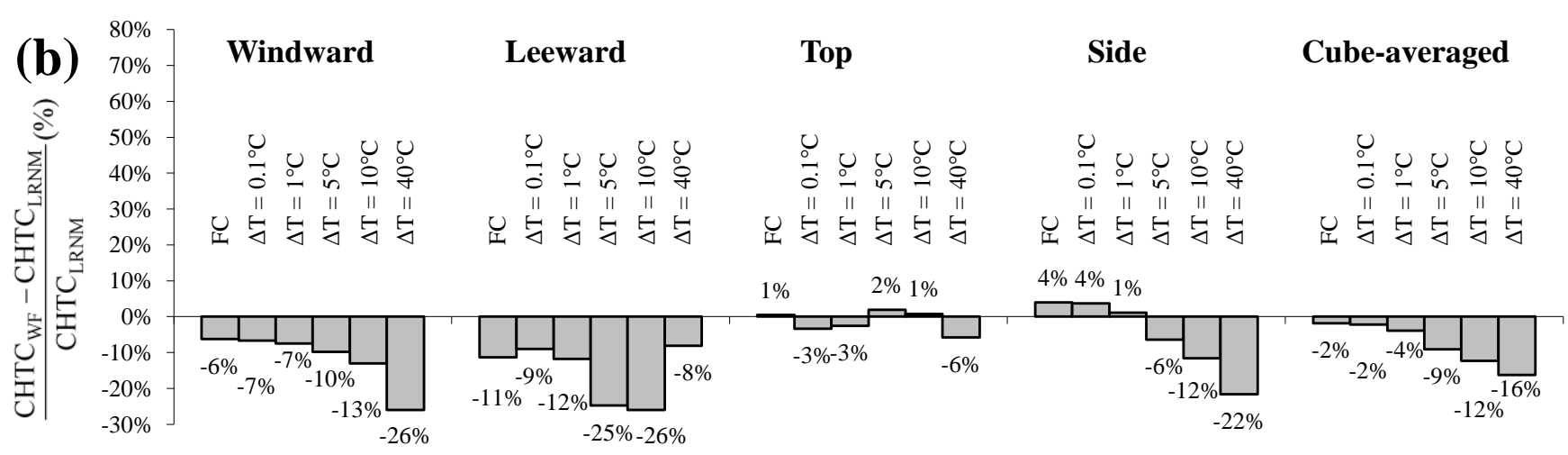

Figure 5. Relative difference of the surface-averaged CHTC of LRNM with that of WFs for different surfaces of the cube, and the cube-averaged value, for (a) SWF; (b) CWF (FC: forced convection). 